\title{
The perspective of doctoral nursing students engaged in mentored international research
}

\author{
Audrey Snyder*1, Gwyneth Milbrath ${ }^{2}$, Tiffany Lee Hood ${ }^{3}$, Raiden Gaul ${ }^{4}$, Kyler Hijmans ${ }^{5}$, Nancy Leahy ${ }^{6}$, Stephanie \\ Matthew ${ }^{7}$ \\ ${ }^{1}$ University of North Carolina, Greensboro, United States \\ ${ }^{2}$ University of Illinois Chicago, United States \\ ${ }^{3}$ Weber State University, United States \\ ${ }^{4}$ Utah Valley University, United States \\ ${ }^{5}$ University of Northern Colorado, United States \\ ${ }^{6}$ John Tyler Community College, United States \\ ${ }^{7}$ George Fox University, United States
}

Received: June 19, 2020

DOI: $10.5430 /$ jnep.v11n1p19
Accepted: August 30, $2020 \quad$ Online Published: September 14, 2020

URL: https://doi.org/10.5430/jnep.v11n1p19

\begin{abstract}
Five doctoral nursing students and their faculty traveled to St. Kitts and Nevis for a study abroad experience to apply research skills outside of a classroom setting as part of a disaster preparedness elective course. Nursing students reflected on their perspectives of conducting a mixed-methods research study in another country. Each student reported positive benefits from the experience, particularly emphasizing the importance of face-to-face mentorship in doing actual research as a part of doctoral studies to supplement research methods learned in online courses. Students also acknowledged challenges and learning opportunities within their experience. International mentored research projects can assist graduate nursing students through the transition from student to independent researcher. The authors believe these types of intensive research experiences should be encouraged and supported within nursing education.
\end{abstract}

Key Words: Mentorship, Doctoral education, Perspective, Nursing, Study Abroad

\section{INTRODUCTION}

Doctoral students are immersed in research courses with the expectation of becoming expert nurse scientists, capable of designing, implementing, analyzing and disseminating the results of projects that will help define nursing knowledge. The purpose of this article is to discuss the perspectives of doctoral nursing students who participated in a mentored, study-abroad elective, and to describe the benefits of participating in an immersive mixed-method research project facilitated by expert faculty.

The doctoral students and faculty who participated in the international research experience authored this paper. A description of the study location and its residents creates a backdrop for the narrative and illustrates how history and culture are integral to defining a population's actions and beliefs. A brief explanation of the research experience is discussed including data collection obstacles that come with working cross-culturally in international locations. Finally,

${ }^{*}$ Correspondence: Audrey Snyder; Email: aesnyde2@uncg.edu; Address: University of North Carolina at Greensboro, P.O. Box 26170 Greensboro, NC 27402, United States. 
participant perspectives of the benefits and challenges of the experience are discussed and implications for nursing education are shared.

\subsection{Background}

Successful nursing Doctor of Philosophy $(\mathrm{PhD})$ and Doctor of Nursing Practice (DNP) programs require a strong curriculum, seasoned research faculty to mentor students, an institutional commitment to doctoral education, and structures in place to support the educational needs of students. ${ }^{[1]}$ Although the need for nurse scientists continues to grow as many tenured and experienced researchers prepare to retire, the number of research-focused doctoral students is in decline and will not be sufficient to replenish or sustain the needed workforce. ${ }^{[2]}$ According to a report on the status of doctoral education, a downward trend in the number of $\mathrm{PhD}$ enrollments has resulted in a 9.6\% decline since 2014, while the enrollment of DNP students has risen by $752 \% .^{[3]}$ The shortage of qualified nurse researchers limits the influence that nursing science can have on the future generation of nurses, and the gap in research expertise experienced with faculty shortages threatens the current $\mathrm{PhD}$ pipeline. ${ }^{[4,5]}$

Doctoral programs are evaluating strategies to enhance curricula and provide the resources needed to foster growth in research skills. While the value of mentorship for doctoral students and faculty has been extensively described in the literature,${ }^{[6,7]}$ the impact of immersive research experiences for doctoral students has not been explored. Most doctoral educational programs employ a traditional, apprenticeship approach to the development of research expertise through the formal dissertation process with a designated research adviser and faculty committee. ${ }^{[8]}$ However, with the growth in online doctoral programs, creating opportunities to work directly with peers and doctoral faculty may help fill the essential need to establish professional connections while honing research skills. The experiences described in this article detail how a study abroad course created an environment that fostered both mentorship and socialization of students as research scholars.

\subsection{Course development}

Within two almost-exclusively online doctoral nursing programs, a hybrid elective course titled Global Health and Disaster Preparedness in the West Indies was held in the summer of 2018 through the University of Northern Colorado (UNCO). Through this course, a mixed-methods needs assessment study was conducted on the islands of St. Kitts and Nevis in the Caribbean, which provided the opportunity to use research skills in a hands-on approach through the guidance of faculty mentorship. To date, no mentored study abroad research studies by doctoral-level nursing students have been identified in the literature.

The evolution of the course offered through the UNCO in St. Kitts and Nevis was initially developed over several years, and is described in detail elsewhere. ${ }^{[9]}$ In 2018, five graduate nursing students from the DNP and $\mathrm{PhD}$ programs registered for the study abroad course. The faculty adapted the course to provide the graduate students with applied research experience as part of their study abroad experience. The faculty coordinated with colleagues at the University of Illinois Chicago (UIC) who planned to conduct a community disaster resilience assessment in collaboration with national disaster management officials. This study expanded upon a similar assessment that was completed in Haiti. ${ }^{[10]}$ Nursing students and a professor from the UNCO joined forces with public health, medicine, and nursing faculty and students from the UIC, creating an interdisciplinary research team of nine students and three faculty.

The faculty demonstrated how to conduct international research in countries with cultural differences, limited resources, and power differentials using the core ethical principles described in the literature of beneficence, respect, autonomy, and justice. ${ }^{[11-13]}$ The literature emphasizes, and the faculty modeled, the importance of building long-term, trusting relationships with local leaders. ${ }^{[11,13-15]}$ Over the course of eleven years, a unique relationship has formed between the people of St. Kitts and Nevis and the course professor from the UNCO. Through many educational and medical trips to the islands, the UNCO professor developed friendships with many high-ranking leaders on the islands. These relationships soon proved to be key in providing opportunities to survey and interview hospital administrators, disaster agency personnel, the former Minister of Health, and other community leaders, and to gain knowledge of the islands, the people, and the culture.

This project was developed in collaboration with local leaders, ensuring that all work completed paralleled the needs of the local community. The long-term goal of this research project was to conduct a needs assessment, which would then be used to create educational programs and tools to help prepare individuals, hospitals, schools, community shelters, and other community centers for disasters. The goal was met and a comprehensive report of the needs assessment was presented to the country leaders the following year.

\subsection{Theoretical framework}

Gardner et al. (2009) developed the Engaging Tomorrow's International Nursing Leaders (ETINL) conceptual model that provides a theoretical framework to support international 
experiential graduate education and mentored research. ${ }^{[16]}$ The ETINL model was developed as part of a blended webbased nursing course, which included a mentored international experiential learning experience similar to the one the authors engaged in. The core concepts of the ETINL model include advocacy, activism, and professional accountability. According to this model, mentored international learning provides the experiential link that bridges theory and practice in a dynamic structured way. ETINL is designed to be applied using diverse learning modalities while supporting the needs of populations in international locations with limited resources. This model illustrates how students engaged in transformational learning experiences gain greater awareness of the nurse's professional role and responsibility to advocate for social justice and the health needs of at-risk populations. Mentoring is a vital component of this model. As faculty shared their expertise, they taught the students about advocacy, activism, and leadership. ${ }^{[16]}$ The faculty modeled how to become life long, self-directed, self-disciplined and reflective scholars who use research to empower vulnerable populations.

\section{Setting}

St. Kitts and Nevis form a small two-island nation in the Eastern Caribbean. Once ruled by the British, this small democratic sovereign state is home to two inactive volcanoes amidst mountainous terrain, rain forests and beaches. When occupied by European forces, the country was valued for its wealth of sugar cane, which was farmed, harvested and processed by slaves until slavery was abolished in 1834 . White plantation owners who held the power in St. Kitts and Nevis oppressed the freed black population. While wealthy white landowners continued to prosper, the ancestors of former slaves were subject to unemployment, poor working conditions and unequal pay as poverty persisted and began to sow the seeds of discontent. These inadequate living conditions led to desperation that fueled an uprising in 1935, followed by decades of activism against the British until St. Kitts and Nevis won their independence in 1982. Kittitians and Nevisians elected representatives for a new political structure and established a social policy that would give universal access to healthcare. ${ }^{[17]}$

With a focus on prevention, healthcare is provided at four hospitals and seventeen community health centers, strategically located throughout the two islands. Each center offers chronic disease management, dental care, and perinatal care. ${ }^{[17]}$ Full-time registered nurses staff all hospitals and clinics. Registered nurses in St. Kitts and Nevis are required to obtain a bachelor's degree, followed by a postgraduate certificate in Nurse Midwifery. ${ }^{[18,19]}$

Published by Sciedu Press
Today, St. Kitts and Nevis remains a sovereign state with a constitutional monarchy. Most of the 50,726 permanent residents live clustered in small towns along the coast and depend on tourism to support their economy. ${ }^{[20]}$ Yet amidst this inviting tropical setting exists a vulnerability to natural hazards. The islands' Caribbean location and topography creates an elevated risk for natural disasters. Earthquakes, tsunamis, hurricanes, flooding and mudslides can occur. The resulting damage to infrastructure can impact transportation routes and access to supplies needed for recovery. For local officials within a resource-limited system, thoughtful organizational, community, and individual planning is an essential component of disaster preparedness. ${ }^{[17]}$

As an important part of the island's culture, religion continues to be a vital part of life. Churches provide a community resource for local residents and additionally serve as a hub of communication and assistance during disasters. Many churches serve as shelters and evacuation sites and create an unofficial network to keep parishioners informed of impending weather events. ${ }^{[21]}$ This remote island environment provided the setting for the study abroad course and research experience. An understanding of the history of the islands was necessary to contextualize the research.

\section{RESEARCH EXPERIENCE}

The team initially met for an online class prior to travel. Course faculty provided students with a course orientation, packing instructions, and an overview of law and culture in St. Kitts and Nevis. Students completed required human subjects research training in order to participate in the research process. The UNCO team arrived in Nevis the day before Tropical Storm Beryl blew by the islands, providing real life experience of the strength of high winds and challenges in the Caribbean. Other than high winds, mild storm surge, and some downed trees, there was no damage to life or property. On day two the UIC team joined the UNCO students. The next morning's orientation at the National Emergency Management Agency (NEMA) prepared the team for the research study.

Institutional review board approval was obtained from both universities prior to conducting the research study. Survey teams consisted of students and faculty from both universities, and staff and volunteers from NEMA in St. Kitts and Nevis Disaster Management Department (NDMD) on Nevis. Quantitative data were collected using a survey which assessed disaster preparedness and knowledge related to disasters. The survey consisted of questions related to disaster knowledge, preparedness, and perceptions, as well as a validated survey tool to measure community resilience. Full methodology and results of the study are reported else- 
where. ${ }^{[21]}$

The majority of quantitative data were collected through community surveys of individuals in randomly selected homes in each parish or district, as well as surveys of persons in local businesses, health centers, and nursing homes, and through participation in community events, such as farmer's markets and festivals. Students traveled to each parish or district, and then walked door-to-door to various households. Many people spend time outside socializing during the daytime hours, and it was convenient to approach people in the street and to ask whether they were willing to participate. The research teams used a standardized verbal consent script, and all participants gave verbal consent prior to participating. A total of 343 community surveys were collected from each of the five parishes in Nevis and the eight districts in St. Kitts.

Qualitative interviews were conducted with both key informants and community informants. Key informants were selected by local leadership to represent officials across various aspects of the community, including health care, tourism, public policy, emergency services, and education. Students had the opportunity to personally interview individuals key to the leadership and organization of St. Kitts and Nevis. Interviews ascertained organizational-level approaches to disaster management, including disaster planning, coordination, and communication. Students were encouraged to first observe an interview, and then conduct one themselves.

Community member interviews were also conducted, giving students the ability to practice and refine interviewing skills. Teams completed qualitative interviews with participants from different levels of income, socioeconomic status, and age ranges in order to gather a wide variety of data that accurately represented the population. Through this process, students gained confidence as they entered public libraries, police stations, schools, and homes, always in groups of at least two for safety, and spoke with individuals from all parts of the country. A total of 40 key and community informant interviews were completed. Through the data collection process, and interviews, specifically, students were able to meet hundreds of individuals from diverse backgrounds, and develop an appreciation for the people of St. Kitts and Nevis.

\section{Discussion OF STUDENT PERSPECTIVES}

The students and faculty developed this manuscript as they reflected on the educational and personal value of the experience both during and after their time in St. Kitts and Nevis. The students all agreed that they gained invaluable insights. This analysis helped students internalize concepts they were able to apply in their own professional roles. The students identified significant challenges and benefits during their discussions and reflective processes. The following discussion highlights the vital educational and personal value of participation in mentored, in-person research experiences, especially for online doctoral education programs.

\subsection{Challenges and learning opportunities}

Students experienced many of the logistical and ethical challenges of international research described in the literature, such as potential cultural misunderstandings, safety issues, the cost of travel, difficulty staying focused, and collecting and transcribing data in a limited amount of time. ${ }^{[11,22]} \mathrm{Al}-$ though the survey tools had been used and validated in prior studies, they had not been tested or validated within St. Kitts and Nevis. The survey was reviewed and approved by leaders in NEMA and NDMD prior to implementation; however, it was not until after volunteers from NEMA completed the survey during the orientation for the study that it was determined that revisions were needed to clarify the language and wording for the population in St. Kitts and Nevis. A determination was made that the research team would need to read the questions to participants and could re-word or explain items as needed to enhance clarity while using the tool; therefore, the delivery and interpretation of the tool varied among research team members. If time had allowed, a pilot study to evaluate the tool would have been beneficial.

Over time, students learned how to effectively communicate with individuals from St. Kitts and Nevis, and respect local customs and practices. For example, students learned from local team members that it was impolite to enter property without permission, and that calling to someone from the street was a more appropriate practice when asking for participation. Surveys were lengthy and took 15-20 minutes to complete. Students learned how to take a communicative approach, taking time to get to know participants on a more personal level, making participants more comfortable during the data collection process. Local disaster management team members often tried to help by interjecting their own interpretation of what many of the questions were asking. This introduced potential bias that may have affected the validity and reliability of the findings. Students also sensed that during key informant interviews, some participants in appointed leadership positions were hesitant to say something that could be considered critical of the government. Assessing this reluctance, students learned how to reassure participants of anonymity.

Communication between groups remained a challenge throughout the experience, as faculty sought to schedule and coordinate experiences. Faculty demonstrated respect for different cultural norms, nursing roles, and education and practice models. It was both challenging and rewarding to 
work with a multidisciplinary team of students and faculty from two universities living in five different states with diverse expertise, education and professional roles. Students felt they would have had a more cohesive group if there had been a more in-depth orientation and if groups from each university would have traveled and been housed together; however, faculty provided many opportunities to explore the islands and visit historical sights to learn more about the country and to help strengthen team bonds. Students also used their strengths to help one another. Students from the UNCO assisted the UIC students with interviewing and qualitative skills, while the UIC students excelled in statistical methods and provided quantitative data analysis.

The students' United States (U.S.)-centered assumptions about Caribbean culture and healthcare were challenged. Students were surprised to learn that despite the island's geographic isolation and finite resources, residents of St. Kitts and Nevis have universal access to free comprehensive primary healthcare within 15 minutes of every household, and have better health outcomes than many areas of the U.S. ${ }^{[17]}$ For example, in 2015 in St. Kitts and Nevis, the neonatal mortality was 8 per 1000 births. In comparison, in 2015 the infant mortality rate in Mississippi was 9.3. ${ }^{[19,23]}$

Students learned that nursing leaders in St. Kitts and Nevis play a central role in their population-based healthcare system. Nurses deliver the majority of newborns and provide free antenatal, postpartum, and women's healthcare in community centers, which is consistent with other Caribbean nations and based on the British model for nursing. ${ }^{[24]} \mathrm{Im}$ munization rates in St. Kitts and Nevis are nearly $100 \%$, and community centers have effective systems for tracking the health status of residents. Communities demonstrate closeknit relationships and unique resilience. Neighbors know and care for one another, there is genuine widespread concern for the wellbeing of the elderly, and community churches are very involved in disaster preparedness. ${ }^{[17]}$

\subsection{Benefits}

Each student reported positive benefits from the experience, particularly emphasizing the importance of face-to-face mentorship while conducting research as a part of doctoral studies to supplement online didactic course content on research methods. While in St. Kitts and Nevis, the students immersed themselves in the research project. Time in the environment provided dedicated space and time for the students to engage in the process of collecting data, facilitating active learning rather than passive learning that is provided through textbooks and lectures. These learning opportunities continued after returning from abroad through the hands-on experience of data analysis under the direct mentorship of experienced

Published by Sciedu Press faculty. Working as a team, students learned how to use

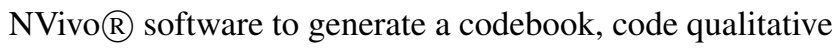
data, and extract themes. As the project concluded, final summaries of the data were presented at various conferences both in the Caribbean and in the U.S. The experience provided the opportunity for students to be involved in all aspects of the research process, from study design and data collection to analysis and presentation.

This experience directly influenced the doctoral dissertation studies of two of the students. One is now exploring international trips with nursing students and another is studying the experience of nurse midwives on St. Kitts and Nevis specifically. Further benefits of this experience included opportunities for publication and presentations through local, regional, national, and international outlets. Students have continued to explore the data for other potential applications of this information.

\section{IMPLICATIONS FOR NURSING EDUCATION}

Numerous implications for nursing education are evident. Direct participation in research and access to faculty while travelling provided an immersive learning experience, and a large volume of knowledge was obtained by the students in a short amount of time. Active participation and engagement in the research methods allowed graduate students to build upon the research experience that they had previously developed in their academic and professional nursing careers. As doctoral candidates and future nursing scientists, understanding the research process and generating novel information related to the field of nursing is a critical component of the objectives of doctoral program curricula.

Additionally, in online educational programs, students often do not have the opportunity to benefit from the face-to-face interactions provided in a traditional on-campus program. The study abroad course provided a means for this group to build relationships among fellow students and for mentormentee relationships to thrive. As classmates, students discussed the doctoral challenges they faced both during and after the trip. They have been able to continually support each other in their journeys toward the doctoral degree and in becoming independent researchers.

Personal preparedness is paramount to a nurse's ability to respond to disasters. The course included content related to disaster preparedness and global health, and students were able to individually assess their own disaster risks based on the location and vulnerability of their homes. Each student developed a personal disaster plan and created a family emergency kit. Additionally, each student completed the Federal Emergency Management Agency (FEMA) Introduction to 
the Command System (ICS) 100 training online. ${ }^{[25]}$ Experience with personal disaster preparedness was useful when conversing with island residents during data collection.

Another unexpected benefit of the course was that students had the opportunity to learn how to lead international service learning experiences. Faculty leaders intentionally discussed their thoughts and processes with the students in order to equip them to lead study abroad experiences in the future. Logistics included how to arrange group travel, food and lodging details, facilitating the interactions with university study abroad departments, prioritizing student safety, and arranging meetings in advance. The students learned that course faculty should know enough about the country and culture to prepare students about the context of the environment. Visiting important historical sites, learning about the history and culture of the country, and engaging with the community before beginning the research project itself added richness and depth to the study abroad course, and validated how important it would be to replicate these experiences in future trips as nursing faculty.

\section{Conclusion}

Through this study abroad course, students studied island residents' experiences of disaster preparedness and also had a transformative experience of their own. Students discovered that they gained new understanding as they discussed, analyzed data, reflected, and wrote about their experiences. Engagement in the research study has created many opportunities for scholarship for students and faculty. These opportunities include presenting and disseminating research, as well as informing educational programs that are being used to improve disaster preparedness and response on the islands of St. Kitts and Nevis. Students agreed the experience was life changing and inspired self-reflection of personal and professional goals. They gained new insights into interprofessional research processes, leadership, ethics, healthcare, and themselves, more than they did in any of the other courses in their doctoral programs.

The opportunity for students to conduct hands-on mixed methods research prior to their dissertation was invaluable. Applying methods learned in coursework greatly increased students' knowledge of the research process and improved each student's confidence. Throughout the experience the faculty continually demonstrated and expressed their respect and admiration for the community, created a tangible excitement, and decreased the level of intimidation for first-time researchers. The course provided a safe learning environment where questions were welcomed, and a love of service spread from instructor to students. The bonds created between students and faculty continue to strengthen, and the love for the people of St. Kitts and Nevis will continue to grow for years to come.

\section{ACKNOWLEDGEMENTS}

The authors wish to express their gratitude to the additional members of the research team from the UIC, the Nevis Disaster Management Department, the National Emergency Management Agency, and the citizens of St. Kitts and Nevis who welcomed us into their communities to conduct research and to learn.

\section{CONFlicts OF INTEREST Disclosure}

The authors declare that there is no conflict of interest.

\section{REFERENCES}

[1] AACN: The research-focused doctoral program in nursing: Pathways to excellence [Internet]. American Association of College of Nursing 2010. Available from: https://www . aacnnursing.org/Portal s/42/Publications/PhDPosition.pdf

[2] Broome ME, Corazzini K. Nurse scientist or nursing scientist: Future considerations for the field. Nursing Outlook [Internet]. 2016; 64(6): 523-524. PMid:27886666 https://doi.org/10.1016/j. outlook.2016.09.008

[3] AACN: The PhD pipeline in nursing: Sustaining the science. American Association of College of Nursing. 2018 [cited 2020 May 26]. Available from: https://www. aacnnursing.org/Portals/42 /news/surveys-data/PhD-Pipeline.pdf

[4] Stanfill AG, Aycock D, Dionne-Odom JN, et al. Strategies and resources for increasing the $\mathrm{PhD}$ pipeline and producing independent nurse scientists. Journal of Nursing Scholarship. 2019; 51(6): 717 726. PMid:31697044 https://doi.org/10.1111/jnu. 12524
[5] Tyndall DE, Forbes TH, Avery JJ, et al. Fostering scholarship in doctoral education: Using a social capital framework to support $\mathrm{PhD}$ student writing groups. Journal of Professional Nursing. 2019; 35(4): 300-304. PMid:31345510 https://doi.org/10.1016/j . profnurs.2019.02.002

[6] Lin J, Chew YR, Toh YP, et al. Mentoring in nursing: An integrative review of commentaires, editorials, and perspective papers. Nurse Educator [Internet]. 2018; 43(1): E1-E5. PMid:28492413 https://doi.org/10.1097/NNE:000000000000389

[7] Mijares L, Baxley SM, Bond ML. Mentoring: A concept analysis. The Journal of Theory Construction and Testing. 2013; 17(1): 23-28.

[8] Bova C, Perry DJ, Kaine AT, et al. Expanding horizons: Onoergan's philosophy as a guide to $\mathrm{PhD}$ program pedagogy: Nursing Outlook [Internet]. 2018; 66(1): 77-83. PMid:29291946 https: //doi.org/10.1016/j.ooutlook.2017.07.003

[9] Milbrath G, Snyder A, Martin M. Interdisciplinary disaster preparedness: Study abroad in St. Kitts and Nevis. Health Emer- 
gency and Disaster Nursing: Advanced online publication. 2018. http://doi.org/10.24298/hedn.2018-0008

[10] Lin J, Budoff A, Dyer A. Acceptability of a modular, communityinformed disaster risk reduction training programme in Delmas, Haiti. The Lancet Global Health [Internet]. 2014 May; 2(S6). https : //doi.org/10.1016/s2214-109x (15) 70028-8

[11] Chiang-Hanisko L, Ross R, Ludwick R, et al. International collaborations in nursing research: Priorities, challenges and rewards. Journal of Research in Nursing [Internet]. 2006; 11(4): 307-322. https://doi.org/10.1177/1744987106065685

[12] Harrowing JN, Mill J, Spiers J, et al. Culture, context and community: Ethical considerations for global nursing research. International Nursing Review. 2010; 57(1): 70-77. PMid:20487477 https://doi.org/10.1111/j.1466-7657.2009.00766.x

[13] O'Keefe LC, Frith KH, Barnby E. Nurse faculty as international research collaborators: International collaboration. Nursing \& Health Sciences. 2017 [cited Jun 1]; 19(1): 119-125. PMid:27781360 https://doi.org/10.1111/nhs.12312

[14] Callister LC, Getmanenko NI, Khalaf I, et al. Collaborative International Research. The Journal of Continuing Education in Nursing. 2006; 37(1): 39-45. PMid:16479848 https://doi.org/10. 392 8/00220124-20060101-04

[15] Opollo JG, Opollo DA, Gray J, et al. Conducting international nursing research: Challenges and opportunities. Nurse Researcher. 2014 [cited Jun 1]; 22(2). PMid:25423939 https://doi.org/10.774 8/nr.22.2.29.e1279

[16] Garner BL, Metcalfe SE, Hallyburton A. International collaboration: A concept model to engage nursing leaders and promote global nursing education partnerships. Nurse Education in Practice. 2009; 9(2): 102-108. PMid:19059008 https://doi.org/10.1016/j. nepr.2008.10.011
[17] Martin ML, Snyder A, Jones AW, et al. West Indies health care and disaster preparedness. Scotts Valley, California: CreateSpace Independent Publishing Platform; 2015.

[18] Brathwaite AF. Policy reform in nurse education and its implementation in the Caribbean region [Internet]. Doctoral dissertation: University of Sheffield. 2017 [cited 2020 May 27].

[19] PAHO: St. Kitts and Nevis: Health in the Americas [Internet]. Pan American Health Organization. 2019 [cited 2020 Jun 1]. Available from: https://www.paho.org/salud-en-las-america $\mathrm{s}-2017 / ? \mathrm{p}=4298$

[20] St. Kitts and Nevis Official Website [Internet]. 2019 [cited 2020 June 1]. Available from: https://www.gov.kn/

[21] Milbrath G, Snyder A, Drzewiecki D, et al. Kitts and Nevis Community Disaster Resiliency Assessment. Report to the Governments of St. Kitts and Nevis. 2019 June.

[22] Capitulo KL. International collaboration in nursing research. Applied Nursing Research [Internet]. 2007; 20(1): 1. PMid:17259036 https://doi.org/10.1016/j.apnr.2006.10.001

[23] CDC: Centers for Disease Control and Prevention: National Center for Health Statistics. 2018 [cited 2020 Jun 1]. Available from: https://www.cdc.gov/nchs/pressroom/states/miss issippi/mississippi.htm

[24] Crespo-Veledon DT. The role and image of midwives in Caribbean society from the colonial period to the present: A critical analysis of the discourse relevant to midwifery in specific hispanophone, anglophone, and francophone contexts [dissertation] [Puerto Rico (Rio Piedras)]: University of Puerto Rico; 2017.

[25] FEMA: Introduction to the Incident Command System. ICS100 [Internet]. Federal Emergency Management Agency. 2019 [cited 2020 Jun 1]. Available from: https://training.fema.gov/is/cou rseoverview . aspx?code $=$ IS $-100 . c$ 